This item was submitted to Loughborough's Research Repository by the author.

Items in Figshare are protected by copyright, with all rights reserved, unless otherwise indicated.

\title{
Numerical and experimental comparison between two different blade configurations of a wind generator
}

PLEASE CITE THE PUBLISHED VERSION

http://dx.doi.org/10.1016/j.compstruct.2015.10.042

PUBLISHER

(c) Elsevier Ltd.

VERSION

AM (Accepted Manuscript)

\section{PUBLISHER STATEMENT}

This work is made available according to the conditions of the Creative Commons Attribution-NonCommercialNoDerivatives 4.0 International (CC BY-NC-ND 4.0) licence. Full details of this licence are available at: https://creativecommons.org/licenses/by-nc-nd/4.0/

\section{LICENCE}

CC BY-NC-ND 4.0

\section{REPOSITORY RECORD}

Alaimo, Andrea, Francesco Lo lacono, Giacomo Navarra, and Giovanni Pipitone. 2019. "Numerical and Experimental Comparison Between Two Different Blade Configurations of a Wind Generator". figshare. https://hdl.handle.net/2134/20234. 


\title{
Numerical and experimental comparison between two different blade configurations of a wind generator
}

\author{
Andrea Alaimo ${ }^{1}$, Francesco Lo Iacono ${ }^{1}$, Giacomo Navarra ${ }^{1}$, Giovanni Pipitone ${ }^{2}$ \\ ${ }^{1}$ Faculty of Engineering and Architecture, University of Enna "Kore" \\ Cittadella Universitaria 94100, Enna, Italy \\ [andrea.alaimo, francesco.loiacono, giacomo.navarra]@unikore.it \\ ${ }^{2}$ School of Civil and Building Engineering, Loughborough University, \\ Loughborough, LE113TU, Leicestershire, UK \\ g.pipitone@lboro.ac.uk.
}

$\begin{array}{ll}\text { Keywords: } & \text { wind energy structures, FEM analysis, experimental dynamic identification, model } \\ \text { updating }\end{array}$ Corresponding author: Giovanni Pipitone

\begin{abstract}
This paper presents a comparison between the structural behaviour of a wind generator with straight blades and a composite prototype of a wind generator with helical blades. Numerical structural analyses are performed by means of FEM models by using ANSYS $^{\circledR}$ Mechanical $^{\mathrm{TM}}$ software package. Furthermore, laboratory dynamic experimental tests are carried out on real scale specimens of the two wind generator configurations in order to find their modal properties in terms of natural frequencies and modal shapes. The results of the experimental campaign are then used to update the numerical models by minimizing an objective function. Total stresses and deformations of the two wind generator configurations, coming from the updated numerical models, are evaluated and compared to quantitatively point out the improvement of the structural behaviour obtained by the use of composite materials.
\end{abstract}

\section{Introduction}

Due to ever increasing demands for cleaner energy sources and government funding incentives, wind energy generation is constantly growing up, intercepting a significant percentage of electrical demand worldwide. Predictions show that the global electric wind capacity will increase with an annual average growth of $20.9 \%$ [1]

Among the different wind turbine layouts and technologies, the market is nowadays dominated by huge three-bladed upwind Horizontal Axis Wind Turbines (HAWTs) provided with gearbox and asynchronous generators. On the other hand, small Vertical Axis Wind Turbines have gained more 
and more interest for their excellent adaptability to the urban environment in terms of visual impact and noise pollution [2].

The main differences between VAWTs and HAWTs is that in VAWTs the main rotor shaft is set vertically and they are characterized to be robust, quiet, omnidirectional, and they do not induce much stress as in the HAVT on the support structure [3]. Moreover, VAVTs can be placed very close one to each other in wind farms, allowing a more efficient use of available space. This is due not only because VAWTs are smaller than HAWTs but rather because of the slowing effect that HAWTs exhibit on the air, forcing designers to separate them ten times their width.

Although VAWTs are not as efficient as HAWTs and dynamic stability problems can occur, they offer improved performances at lower wind speeds because of their very low starting torque if compared to traditional HAWTs [4].

Among the main benefits, a lower revolution velocity at higher wind speeds can be observed, resulting in a quieter turbine, suitable for residential environments. Furthermore, VAWTs are safer and easier to build and they can be assembled closer to the ground since vertical turbine handles turbulence much better than the horizontal one.

The Major drawbacks are the tendency to stall under gusty winds, the small torque that can be produced in each revolution and the huge bending moments that arise on the blades. Moreover, the blades are also very prone to fatigue issue ([5],[6]).

There are basically two different categories of VAWTs, the Savonius and the Darrieus layout. The Savonius type is known as a drag-type wind turbine characterized by a very simple structure and, because of its operational independency from the wind direction, it represents one of the most aged vertical axis turbine layout able to convert the wind energy into mechanical one ([7],[8])].

On the other hand a Darrieus type VAWT generates the torque by means of the aerodynamic forces that arise on the blades due to the wind. More particularly the rotation of the turbine generates a head wind that combines with the actual wind forming the apparent wind. If the angle of attack of the apparent wind on the blade is larger than zero, the lift force has a forward component on the blades that allows to propel the turbine.

In spite of the structural simplicity of Darrieus type wind turbine, the understanding of the their mechanical behaviour is mandatory in order to reduce the overall weight of the structure, to avoid resonance and other dynamical issues. Thus, numerical and experimental studies have been performed to characterise the structural behaviour of Darrieus VAWTs ([9]-[12]).

On the aforementioned basis, in this paper a comparison between the structural behaviour of two Darrieus type VAWT configurations is presented. The first layout is represented by a commercial wind generator made up by three NACA airfoil section straight blades manufactured in aluminium 
alloy and steel. The second configuration is represented by a composite prototype of Darrieus VAWT made-up by three composite helical blades, whose final geometry stems from a CFD investigation performed by the authors [13], and manufactured at the University of Enna "Kore".

Numerical structural analyses are performed by means of FE models obtained by using ANSYS ${ }^{\circledR}$ Mechanical $^{\mathrm{TM}}$ software package. Furthermore, dynamic experimental tests are carried out on the real scale specimens for both the two wind generator configurations in order to find their dynamic responses in terms of natural frequencies and modal shapes. The results of the experimental campaign are then used to update the numerical models by minimizing an objective function based on the differences between numerical and experimental results. The updated FE models have allowed to compare the mechanical behaviour of the two different configurations in terms of stresses and deformations. The structural improvements coming from the use of composite material for the helical configuration are then pointed out.

\section{Geometry of the tested blades and FE Models}

The aim of this section is to describe the geometry and the FE model of the two Darrieus VAWT configurations. At first, the geometry of the straight blade configuration is presented as well as the material used and the FE model. Then the helical blade configuration is described highlighting for both configurations how the constraints, loadings and interface conditions are modeled by means of ANSYS $^{\circledR}$ Mechanical $^{\mathrm{TM}}$ software package.

\subsection{Geometry and FE model of the straight blade configuration}

The straight blades configuration is characterized by a blade with two cylindrical aluminium spars having external diameter of $60 \mathrm{~mm}$ and $32 \mathrm{~mm}$ and thickness $4 \mathrm{~mm}$ and $3 \mathrm{~mm}$ respectively. The aluminium skin of the blade is $1 \mathrm{~mm}$ thick. The blades are connected to the main generator by means of two cylindrical steel barrels, having diameter $14 \mathrm{~mm}$ and covered by a $3 \mathrm{~mm}$ thick aluminium skin. The overall weight of the blade is $6,7 \mathrm{Kg}$. The main geometric characteristics of the straight blade are shown in Figure 1.

The FE model is obtained by means of a 3D structured mesh made up by 102.777 nodes and 20.627 tetrahedral elements, characterized by a total minimum dimension of 1,6 mm. More particularly, each components of the blade structure is meshed accordingly to the following specifications:

- $\quad$ each steel barrel is modeled with 557 tetrahedral elements and a total number of 1687 nodes;

- $\quad$ the two aluminum skins of the blade supports are meshed by 3376 tetrahedral elements and 20584 nodes; 
- $\quad$ the main front aluminum spar is modeled with 3948 tetrahedral elements and a total number of 26710 nodes;

- $\quad$ the rear aluminum spar is modeled with 3626 tetrahedral elements and 23495 nodes;

- $\quad$ the aluminum skin of the blade is meshed with 2914 elements and 19421 nodes;

- $\quad$ the rotor is modeled with 6206 elements and 10880 nodes;

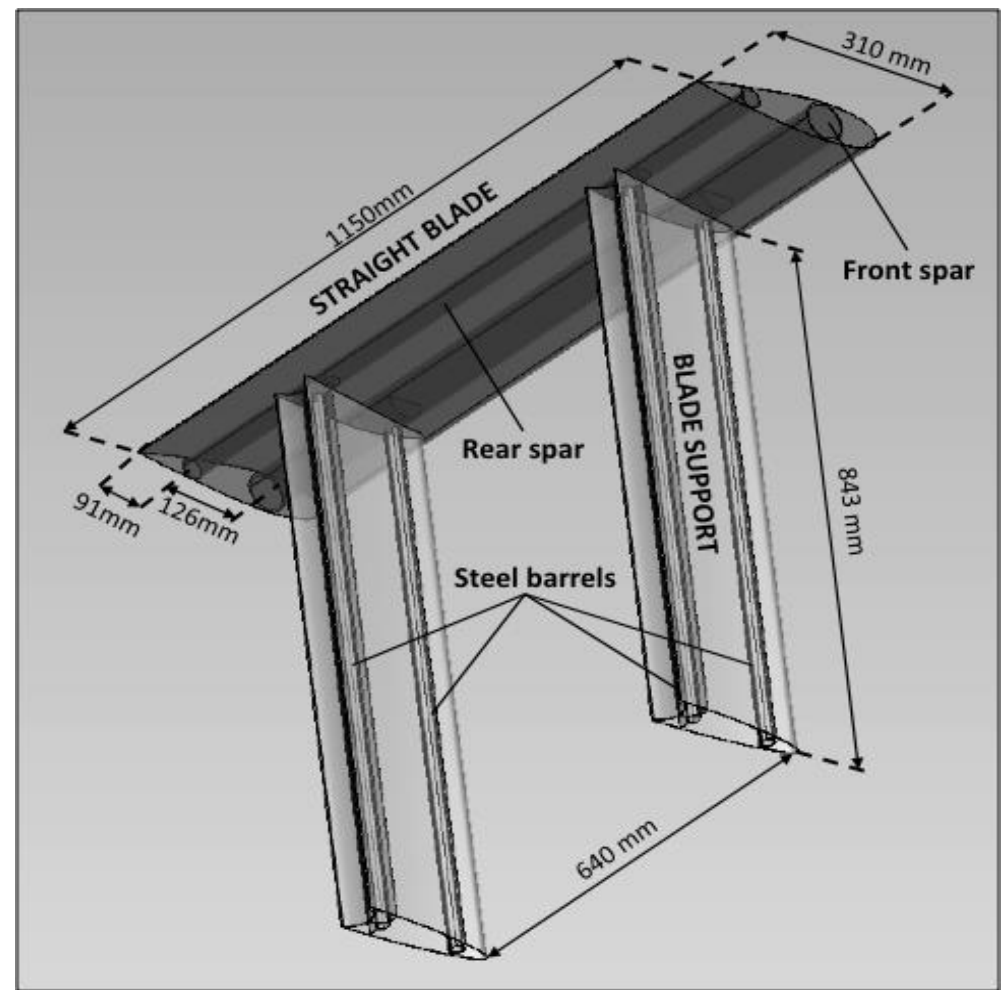

Figure 1. Straight blade geometry and components.

The material properties used for the aluminium and steel are those included in ANSYS ${ }^{\circledR}$ Mechanical $^{\mathrm{TM}}$ software database [14]. Thus for the aluminium components, i.e. the front and rear spar and the blade and support skins, the following material properties are used for the preliminary numerical analyses: Young's Modulus aluminium $E_{\text {alum }}=71 \mathrm{GPa}$, Tensile Ultimate Strength aluminium $\sigma_{\text {alum }}=310 \mathrm{MPa}$, Poisson's ratio aluminium $v_{\text {alum }}=0.33$, mass density aluminium $\rho_{\text {alum }}=2,77 \cdot 10^{-6} \mathrm{~kg} / \mathrm{mm}^{3}$, Young's Modulus steel $E_{\text {steel }}=200 \mathrm{GPa}$, Tensile Ultimate Strength steel $\sigma_{\text {steel }}=460 \mathrm{MPa}$, Poisson's ratio steel $v_{\text {steel }}=0.3$, mass density steel $\rho_{\text {steel }}=7,85 \cdot 10^{-6} \mathrm{~kg} / \mathrm{mm}^{3}$.

As shown in Figure 1, the straight blade configuration is made up by different components assembled one to each other by means of different contact conditions. Thus, the main issue related to the FE model was the identification of the contact regions and the proper modelling of the interface conditions. As deeply described in the following sections, the uncertainty related to the interface modelling has required the model updating and has drawn the choice of the parameters in the updated model. In the following the interface conditions, used to model the assembling of the 
straight blade components, are briefly summarized in the following and shown in details in Figure 2:

- contact between the steel barrel and the two spars is modeled as perfectly bonded interface (Contact Region 1 - CR1);

- $\quad$ contact between the two skins of the blade supports and the skin of the blade is modeled as perfectly bonded interface (Contact Region 2-CR2);

- $\quad$ contacts regions between the steel barrels and the skins of the blade supports are considered to be frictionless since the two different components can slide one to each other (Contact Region $3-\mathrm{CR} 3)$;

- contact between the two spars and the skin of the blade is modeled as perfectly bonded interface (Contact Region 4 - CR4);

- contact between the blade support and the rotor is modeled as perfectly bonded interface (Contact Region 5-CR5);

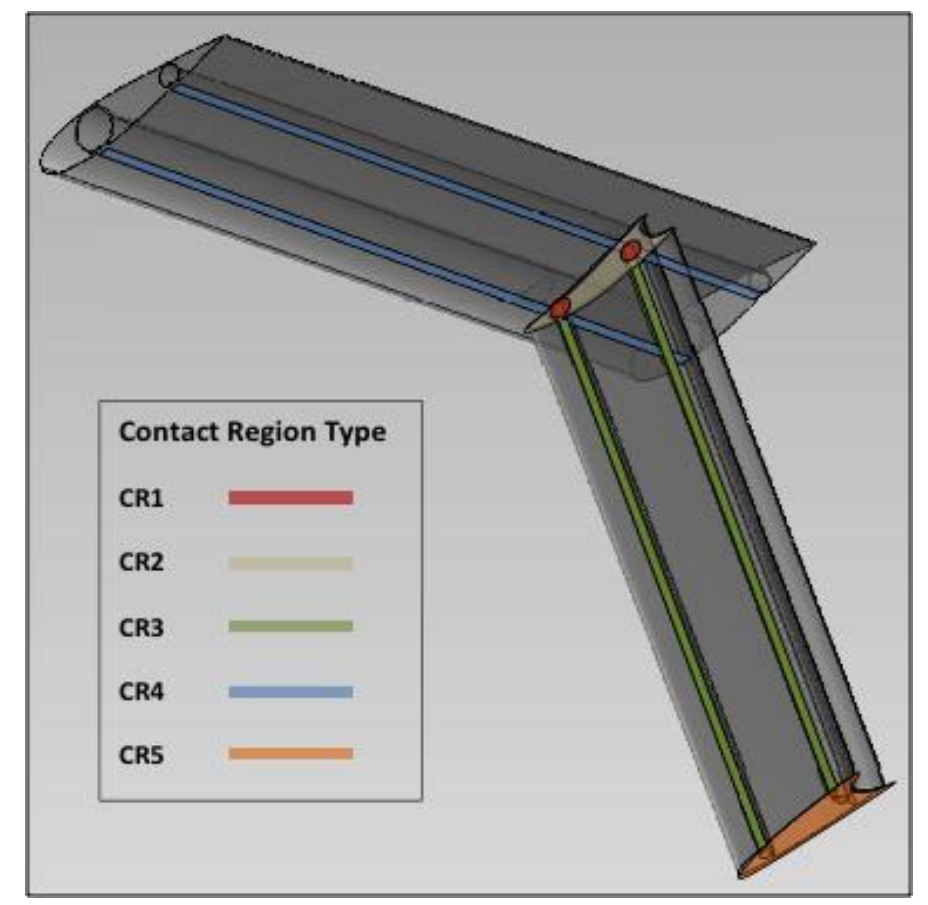

Figure 2. Straight blade components assembly and contact regions.

\subsection{Geometry and FE model of helical blades configuration}

The geometry and the main components of the helical blade configuration is shown in Figure 3 . The final assembling is obtained by using the same blade supports and the same rotor as for the straight configuration while the helical blade is made up in composite material, whose material properties and layout will be defined in the following. As shown in Figure 3, the assembling between the helical blade and the blade supports has been obtained by rotating one of the support of an angle $\alpha=35^{\circ}$. The airfoil used for the helical blade is the NACA 0021, the same as for the straight blade, 
and it is characterized by the same chord length as for the straight configuration. As pointed out in Figure 3, the overall blade span of the helical configuration is the same as for the straight one.

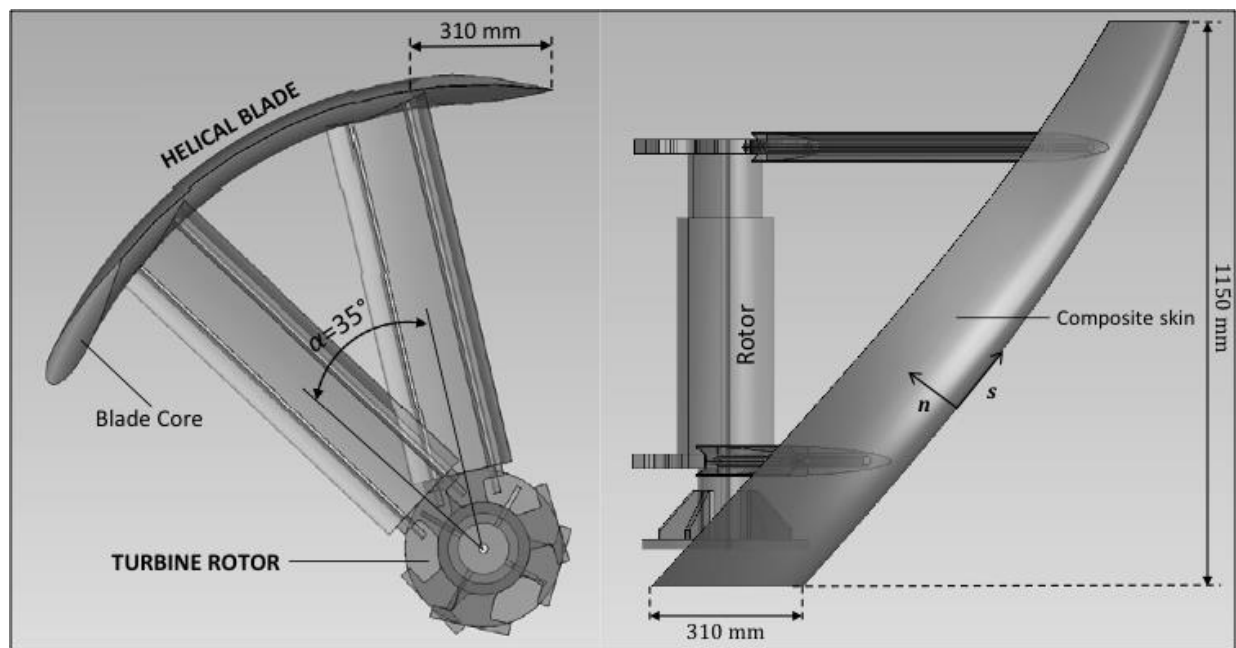

Figure 3. Helical blade geometry and components, top view (left) - side view (right).

The composite helical blade is made up by an inner polystyrene core characterised by Young's modulus $E_{p}=8,43 \mathrm{MPa}$, Poisson's ratio $v_{p}=0.14$ and mass density $\rho_{p}=3 \cdot 10^{-8} \mathrm{~kg} / \mathrm{mm}^{3}$, manufactured through a CNC milling machine, see Figure 4.

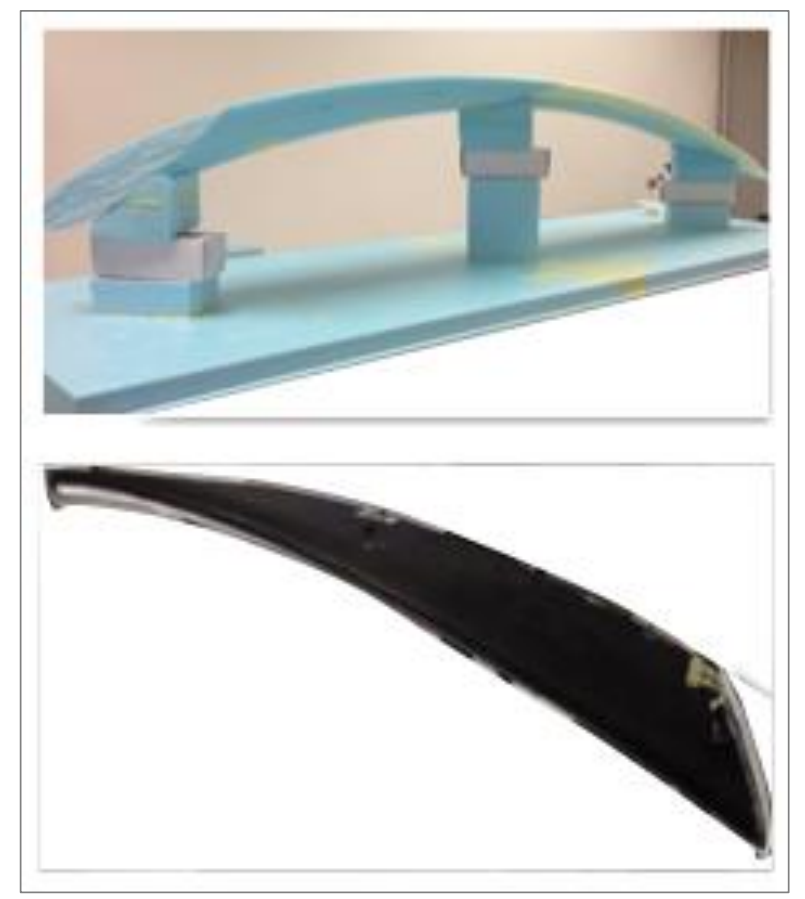

Figure 4. Polystyrene blade core (top) - composite blade (bottom).

The blade skin is fabricated with an hybrid composite laminate obtained by hand laying up E-glass and carbon fibre woven fabrics with epoxy resin matrix. Hexcel Hexforce ${ }^{\circledR} 1035$ twill E-glass weave fabric and Hexforce ${ }^{\circledR}$ Tela 43199 plain carbon waive fabric are used to reinforce SX 10 epoxy cured with medium hardener. As mentioned above, wet hand layup is applied to fabricate the blade skin with the following layup $\left[\mathrm{GC}_{2}\right]$ and the fabric oriented accordingly to the curvilinear 
coordinate $s$ running along the blade leading edge line, see Figure 3 (right). The blade was cured at ambient temperature for 48 hours before cutting and refining the trailing edge and the two blade tips. After the curing process the overall weight of the helical blade resulted in $1,7 \mathrm{Kg}$, approximately $25 \%$ the weight of the metallic straight blade.

The mesh used to model the helical configuration is obtained by both tetrahedral and shell elements. In fact, 17408 tetrahedral and 2870 shell finite elements are used to obtain the FE model and the discretization of the helical blade configuration differs from the straight one only for the mesh used to model the blade. More particularly, the rotor, the steel barrels and the blade supports are modelled by using the same mesh as for the straight blade turbine while the blade itself is modelled by using 2860 shell elements and 2919 nodes for the composite skin and 4399 tetrahedral elements and 22942 nodes for the blade core.

Also the contact regions for the helical blade configuration are the same as for the straight one with the only exception for the interface between the composite skin and the core that is modeled as perfectly bonded region.

\subsection{Models constraints and loadings}

Aiming at characterising and comparing the mechanical behaviour of the two Vertical Axis Wind Turbine, the actual loads arising from an angular velocity $\omega=31 \mathrm{rad} / \mathrm{s}$ are considered. This rotational velocity corresponds to the maximum operative condition certified for the commercial straight blade Darrieus wind turbine.

Thus, in order to simulate the inertial loads associated to the turbine rotation and to the weight of the structures, the following constraint and boundary conditions are applied to the structures.

Cylindrical constraints are applied on the inner cylindrical surface of the rotor as shown in Figure 5.

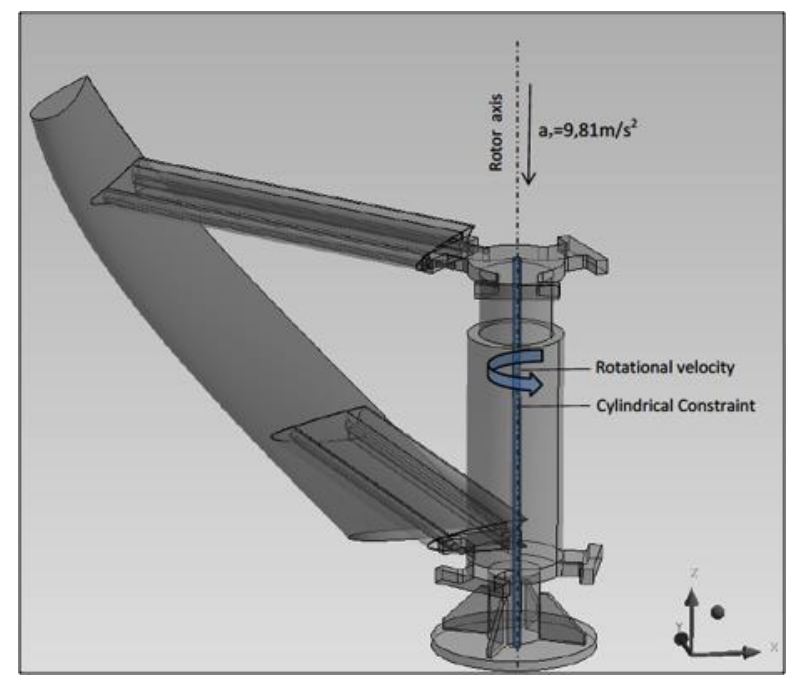

Figure 5. Model boundary conditions and loading for the static analysis.

All the three components, radial, tangential and axial, are set to fixed condition. Moreover the acceleration of gravity is imposed along the z-axis and a rotational velocity with magnitude $31 \mathrm{rad} / \mathrm{s}$ 
is set around the $\mathrm{z}$-axis aiming to simulate that the whole model spins about the rotor axis at the given rate. All the boundary conditions and loading are shown in Figure 5.

\section{Numerical and experimental modal analysis}

This section discusses the modal analyses performed both numerically and experimentally on the two different blade configurations. The comparison between the results obtained by means of the FE simulations and the experimental campaign sets the basis for the model updating presented in the next section.

More particularly, the first subsection presents the responses in the frequency domain obtained numerically by means of the Finite Element models described before, while the second subsection describes, firstly, the experimental setup for both configurations and, then, the experimental results obtained in the frequency domain.

\subsection{Numerical Modal results}

Aiming at evaluating the modal responses, the two different blades are modelled with the same mesh used for the static structural analysis with the only exception that in the modal analysis the rotor structure has been removed. Thus, in order to restore the proper connection between the blade supports and the generator, since it is possible to assume that the stiffness of the rotor is much higher than that of the wing's assembly, clamped constraints are applied at the blade supports end side, actually connected to the rotor.

In Table 1 the first three natural frequencies obtained for the two blade configurations are listed.

Table 1. numerical natural frequencies for both blade configurations

\begin{tabular}{|l|c|c|c|}
\hline Blade Config. & First mode $(\mathrm{Hz})$ & Second mode $(\mathrm{Hz})$ & Third mode $(\mathrm{Hz})$ \\
\hline Straight blade & 21.66 & 40.89 & 49.02 \\
\hline Helical blade & 24.49 & 47.87 & 64.98 \\
\hline
\end{tabular}

This results show that the modal frequencies related to the helical configuration are higher than the straight configuration, thus highlighting the stiffer behaviour introduced by the use of composite materials. Moreover this behaviour increases the gap between the first natural frequency and operative frequency range of the turbine that spans the interval $0 \div 5 \mathrm{~Hz}$.

\subsection{Experimental Modal setup and results}

This subsection shows the setup and the results obtained from experimental modal tests conducted on both straight blade and helical blade turbine configurations. 
The experimental campaign has been performed at the Experimental Dynamic Laboratory of the University of Enna "Kore" in order to find the real natural frequencies of the blades, the correspondent modal shapes and thus to set the basis for the FE model updating.

The experimental setups are schematically described in Figure 6 and Figure 8 for the straight and helical blade configurations, respectively. Each blade is equipped with uniaxial IEPE piezoelectric accelerometers, model type PCB T33B50, differently oriented in order to identify the blade vibrations and to correctly find the mode shapes of the structures.

More particularly, the straight blade has been sensorized by means of 7 accelerometers oriented in such a way accelerometers 1,3,5 and 6, shown in Figure 6, allow to investigate the accelerations on the radial plane, passing from the chord line of the blade and the longitudinal axis of the blade supports. Accelerometers 2, 4 and 7, shown in Figure 6, are instead perpendicular to the radial plane and allow to catch the accelerations of the structure along the out of plane direction.

The accelerometer positions for the helical blade experimental setup is almost the same as for the straight blade configuration, see Figure 8 . The only difference is represented by one more accelerometer, the number 8 shown in Figure 8, added because of symmetry issues.

Hammer tests are then performed by means of an instrumented impulse Hammer PCB model 086C30 and the analogue signals from the sensors have been conditioned and acquired by means of National Instruments (NI) PXIe system equipped with a high resolution NI data acquisition board model NI PXIe 4499 and saved for post-processing purposes. In order to detect the different modal shapes, several positions and directions for the input force are used for the experimental tests, listed for the sake of completeness in Table 2 and shown in Figure 6 and Figure 8.

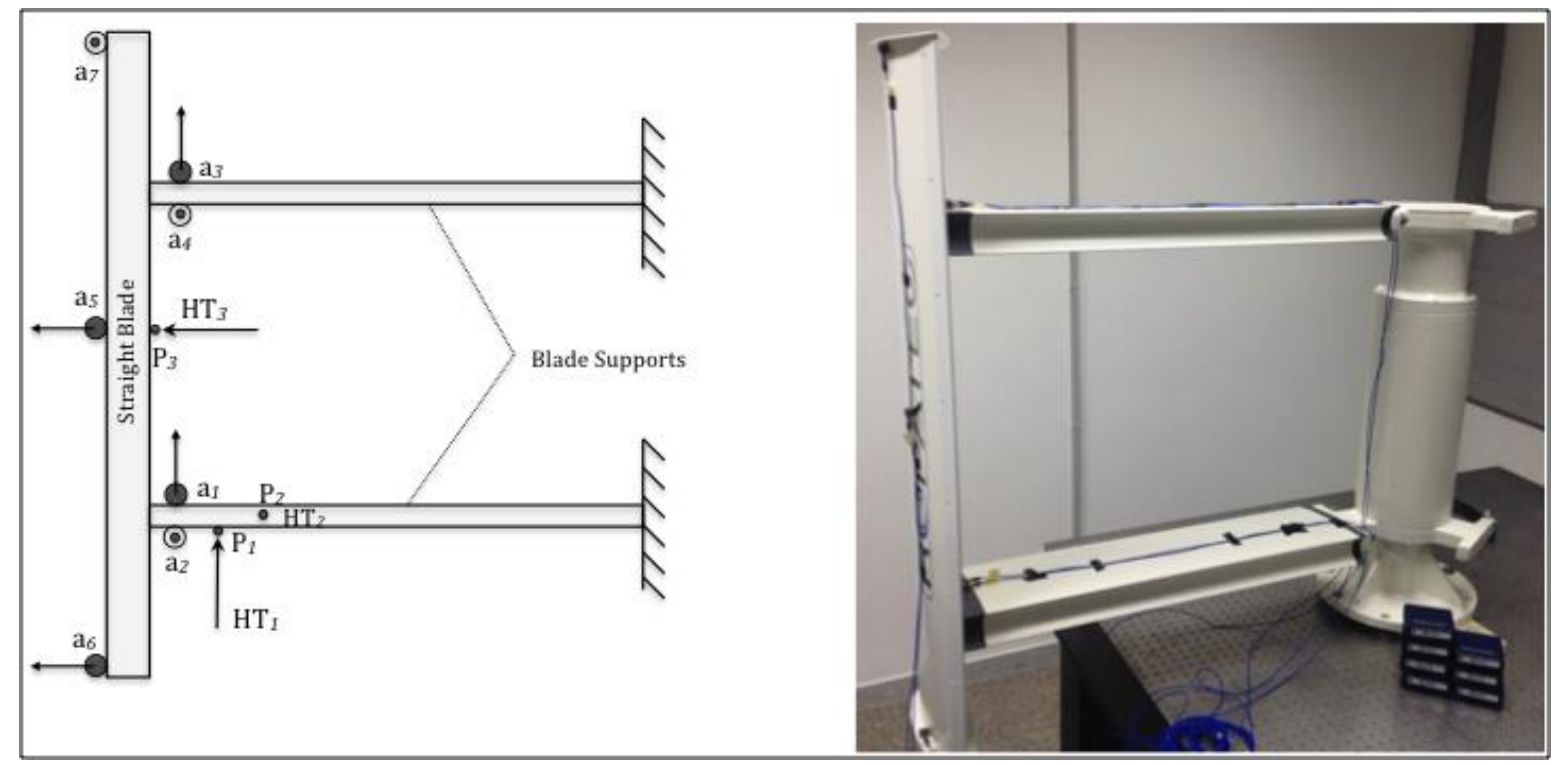

Figure 6. Layout of the experimental test for the straight blade (left); Experimental setup (right). 
Table 2. Input force position $\mathrm{P}_{i}$ and direction referred to acceleration orientation $\mathrm{a}_{i}$.

\begin{tabular}{|l|c|c|c|}
\hline Blade Config. & Hammer Test 1-HT & Hammer Test $2-H T_{2}$ & Hammer Test 3-HT \\
\hline Straight blade & $\mathbf{P}_{1}-\mathbf{a}_{1}$ & $\mathrm{P}_{2}-\mathrm{a}_{2}$ & $\mathrm{P}_{3}-\mathrm{a}_{5}$ \\
\hline Helical blade & $\mathrm{P}_{1}-\mathrm{a}_{1}$ & $\mathbf{P}_{2}-\mathbf{a}_{2}$ & $\mathrm{P}_{3}-\mathrm{a}_{5}$ \\
\hline
\end{tabular}

For each test 10 impulses acceleration time histories responses are acquired in order to compute averaged Frequency Response Functions (FRF). Time domain is characterized by a length of $10 \mathrm{~s}$ and a sample frequency of $2 \mathrm{kHz}$, chosen in order to avoid aliasing at least for the first three natural frequencies of the blades.

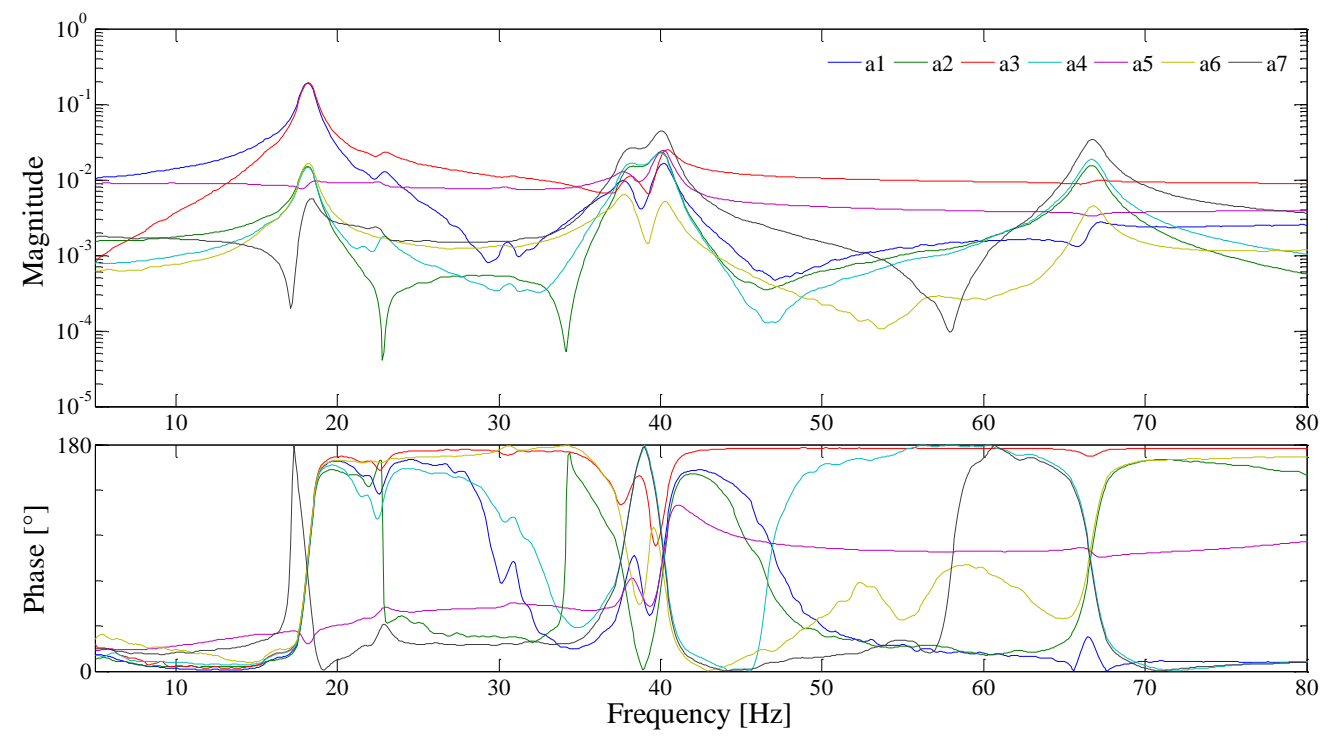

Figure 7. FRF related to the straight blade configuration

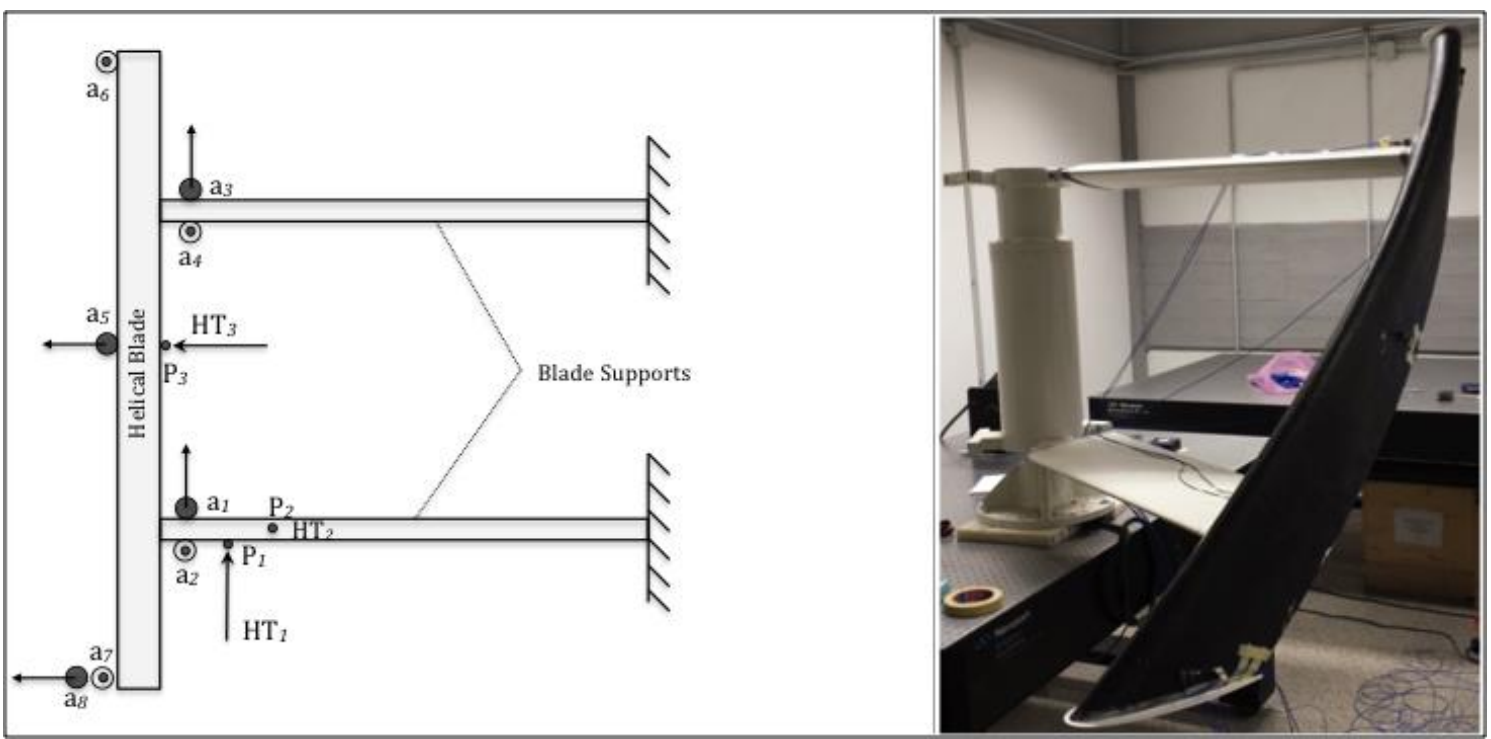

Figure 8. Layout of the experimental test for the helical blade (left); Experimental setup (right).

Post processing analyses consist of detrending, band pass digital filtering with zero phase shift, windowing and FRF computations by using a MATLAB ${ }^{\circledR}$ software. Results for the straight blade, 
corresponding to Hammer test 1, are shown for each accelerometer in Figure 7 in terms of amplitude and phase in the frequency domain. Figure 9 shows the results for the helical blade corresponding to Hammer test 2.

The obtained first three natural frequencies for both blade configurations are listed in Table 3 .

Experimental results are then used as a reference for the updating of the numerical FE models, as deeply discussed in the following section.

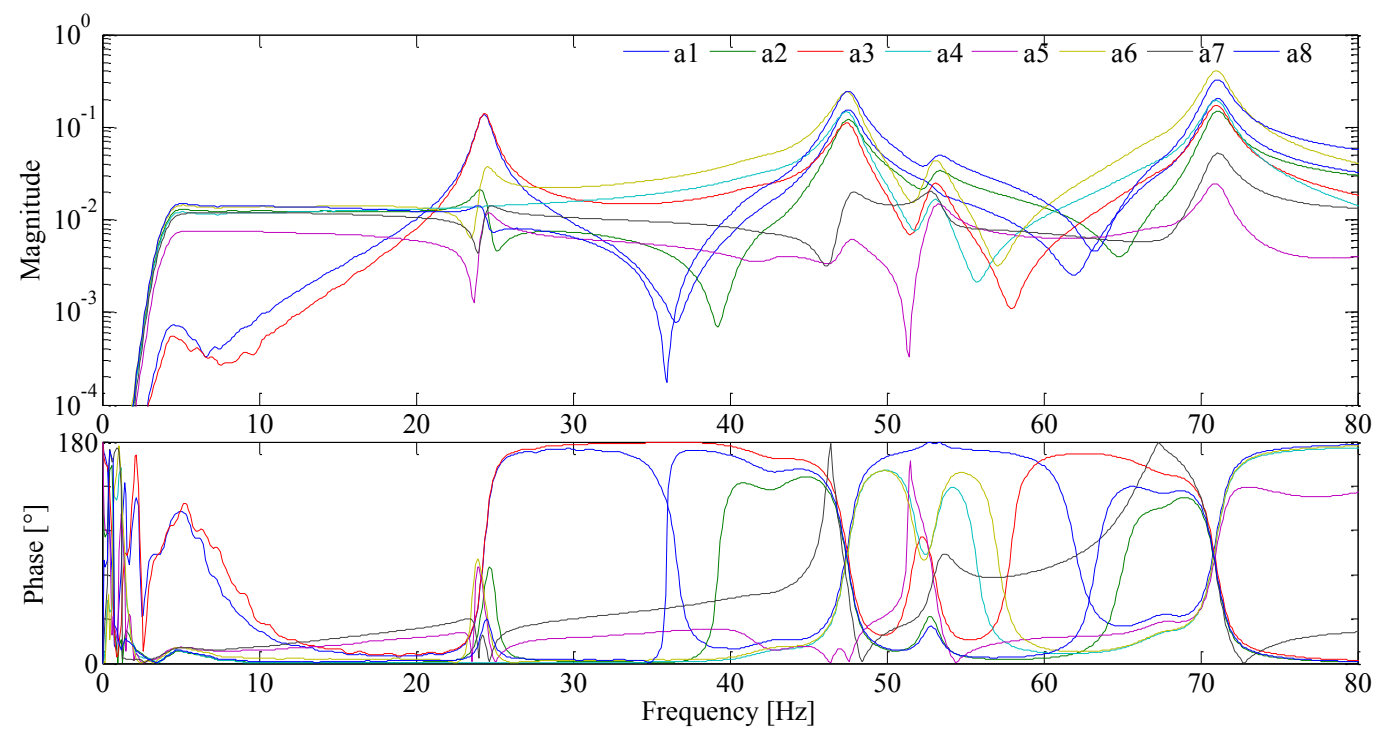

Figure 9. FRF related to the helical blade configuration

Table 3. Experimental natural frequencies for both blade configurations

\begin{tabular}{|l|c|c|c|}
\hline Blade Conf. & First mode $(\mathrm{Hz})$ & Second mode $(\mathrm{Hz})$ & Third mode $(\mathrm{Hz})$ \\
\hline Straight blade & 18.20 & 37.80 & 40.25 \\
\hline Helical blade & 24.30 & 47.50 & 53.10 \\
\hline
\end{tabular}

\section{Model updating}

In this section a comparison between the numerical results and the experimental test is performed. Namely, the values of the first three natural frequencies obtained by experimental results are compared with the correspondent ones obtained by numerical analyses. As described in section 2, the FE modelling of the blade supports and of the straight metallic blade has involved lots of interfaces between the different components, deeply characterized by uncertainties in the accurate modelling of the contact conditions. On the other hand, the composite blade design, modelling and manufacturing has been properly addressed, since very accurate material properties were available as well the bonding interface conditions between the blade skin and the core. On the aforementioned basis, in this paper the differences between the numerical model and the experimental one have been ascribed only to the mechanical properties of the metallic components, 
i.e. the steel and aluminium components, and thus the modal updating has been performed by considering as updating parameters the Young's moduli of steel and aluminium [15]-[20]. In order to correctly evaluate the elasticity modulus that would give the updated finite-element model, the objective function reported in eq. (1) is then minimized. The objective function measures the distance between modal frequencies computed by experimental tests and finite-element-model [19].

$$
J=\sum_{i=1}^{3} \frac{\left(f_{\text {exp }, i}-f_{\text {num }, i}\right)^{2}}{f_{\text {exp }, i}^{2}}
$$

The comparison between the three frequencies obtained by numerical analyses and the ones obtained by experimental tests [21] are reported, together with the corresponding value of $J$, in Table 4 and Table 5 for the straight blade and for the helical blade, respectively. As expected, the model frequencies are quite different from the experimental ones, resulting in percentage errors of the order of $20 \%$ for both cases. This can be explained because the Young's moduli of the material used in the FEM model have been chosen to be equal to standard literature ones.

Table 4 Comparison between the experimental frequency and the numerical frequency for straight blade

\begin{tabular}{|l|c|c|c|c|c|}
\cline { 3 - 6 } \multicolumn{2}{c|}{} & \multicolumn{2}{c|}{ before updating } & \multicolumn{2}{c|}{ after updating } \\
\hline Modal response & $f_{\exp }[\mathrm{Hz}]$ & $f_{\text {num }}[\mathrm{Hz}]$ & $\%$ error & $f_{\text {num }}[\mathrm{Hz}]$ & $\%$ error \\
\hline First mode & 18.20 & 21.66 & $19 \%$ & 19.02 & $4 \%$ \\
\hline Second mode & 37.80 & 40.89 & $8 \%$ & 36.53 & $-3 \%$ \\
\hline Third mode & 40.25 & 49.02 & $22 \%$ & 43.18 & $7 \%$ \\
\cline { 3 - 6 }
\end{tabular}

Table 5 Comparison between the experimental frequency and the numerical frequency for helical blade

\begin{tabular}{|l|c|c|c|c|c|}
\cline { 3 - 6 } \multicolumn{2}{c|}{} & \multicolumn{2}{c|}{ before updating } & \multicolumn{2}{c|}{ after updating } \\
\hline Modal response & $f_{\exp }[\mathrm{Hz}]$ & $f_{\text {num }}[\mathrm{Hz}]$ & $\%$ error & $f_{\text {num }}[\mathrm{Hz}]$ & $\%$ error \\
\hline First mode & 24.30 & 24.49 & $2 \%$ & 21.97 & $8 \%$ \\
\hline Second mode & 47.50 & 47.87 & $0 \%$ & 42.59 & $11 \%$ \\
\hline Third mode & 53.10 & 64.98 & $23 \%$ & 56.57 & $-9 \%$ \\
\hline
\end{tabular}

The FEM model updating have been conducted by means of a parametric analysis where the values of the materials Young's moduli have been varied accordingly to the values reported in Table 6 and the natural frequencies of the models have been computed together with the value of the objective function $J[22]$.

The different values of $J$, calculated by the parametric modal simulation, have been analysed by means of a two dimensional cubic interpolation. Figure 10 and the Figure 11 show the trend of the $J$ function for the straight blade and helical blade respectively after the interpolation procedure.

The values of the Young modules of the aluminium and steel which minimize the objective function in eq. (1) in the case of straight blade have been evaluated as $E_{\text {steel }}=158 \mathrm{GPa}$ and $\mathrm{E}_{\text {alum }}=57.8 \mathrm{GPa}$. 
Figure 10 reports the miminum point and in Table 4 the updated frequencies, along with the percentage error and the minimum value of the objective function are reported.

Table 6. Young's moduli values used for the modal updating.

\begin{tabular}{|c|c|}
\hline $\mathrm{E}_{\text {steel }}(\mathrm{GPa})$ & $\mathrm{E}_{\text {alum }}(\mathrm{GPa})$ \\
\hline 200 & 71 \\
\hline 220 & 78 \\
\hline 180 & 63.9 \\
\hline 170 & 60.4 \\
\hline 160 & 56.8 \\
\hline 150 & 49.7 \\
\hline 140 & 43.2 \\
\hline 130 & \\
\hline
\end{tabular}

In the case of helical blades the Young moduli which correspond to the minimum value of the objective function are $\mathrm{E}_{\text {steel }}=148 \mathrm{GPa}, \mathrm{E}_{\mathrm{alum}}=55.5 \mathrm{GPa}$, as depicted in Figure 11. Table 5 reports the updated frequencies, along with the percentage error and the minimum value of the objective function.

In order to asses that the numerical natural frequencies obtained after the updating procedures are associated to the same modes coming from experimental analyses, a comparison between the modal shapes obtained numerically and experimentally, for both the straight and helical blade configurations, is provided. Thus, in Figure 12 and

Mode 1

Figure 13 the numerical modal shapes are firstly plotted for the first three natural frequencies for the straight and helical blades respectively. In order to highlight the nature of the modal shapes, the undeformed configuration is reported in dashed lines. It is possible to observe that the first mode is pure bending in the $y-z$ plane for both straight and helical configuration. Mode 2, instead, points out a coupling between a bending, in the $x-y$ plane, and twisting mode, around the $y$ axis, while the third natural frequency is associated to a pure twisting mode around the y-axis.

Lastly in Table 7 and

Table 8 the comparison between the numerical and experimental modal shapes for straight and helical blades, respectively, are presented in terms of MAC (Modal Assurance Criterion) index. It is possible to observe that a very high correspondence is obtained in both cases for the first modal 
shape, while for second and third modal shape MAC index show a good agreement between experimental and numerical modal shape only in case of straight blade.

Table 7. Experimental and numerical modal shapes comparison in terms of MAC index - straight blade

\begin{tabular}{|c|c|c|c|c|}
\hline & & \multicolumn{3}{|c|}{ Experimental results } \\
\hline & & $18.20 \mathrm{~Hz}$ & $37.80 \mathrm{~Hz}$ & 40.25 \\
\hline \multirow{3}{*}{$\begin{array}{l}\text { Numerical } \\
\text { results }\end{array}$} & $19.02 \mathrm{~Hz}$ & 0.970 & 0.002 & 0.001 \\
\hline & $36.53 \mathrm{~Hz}$ & 0.130 & 0.658 & 0.371 \\
\hline & $43.18 \mathrm{~Hz}$ & 0.277 & 0.063 & 0.538 \\
\hline
\end{tabular}

Table 8. Experimental and numerical modal shapes comparison in terms of MAC index - helical blade

\begin{tabular}{|cc|c|c|c|}
\cline { 3 - 5 } \multicolumn{1}{c|}{} & \multicolumn{3}{c|}{ Experimental results } \\
\hline \multirow{2}{*}{ Numerical } & $24.30 \mathrm{~Hz}$ & $47.50 \mathrm{~Hz}$ & 53.10 \\
\hline results & $21.97 \mathrm{~Hz}$ & 0.959 & 0.012 & 0.015 \\
\cline { 3 - 5 } & $42.59 \mathrm{~Hz}$ & 0.029 & 0.365 & 0.173 \\
\cline { 3 - 5 } & $56.57 \mathrm{~Hz}$ & 0.060 & 0.046 & 0.243 \\
\hline
\end{tabular}

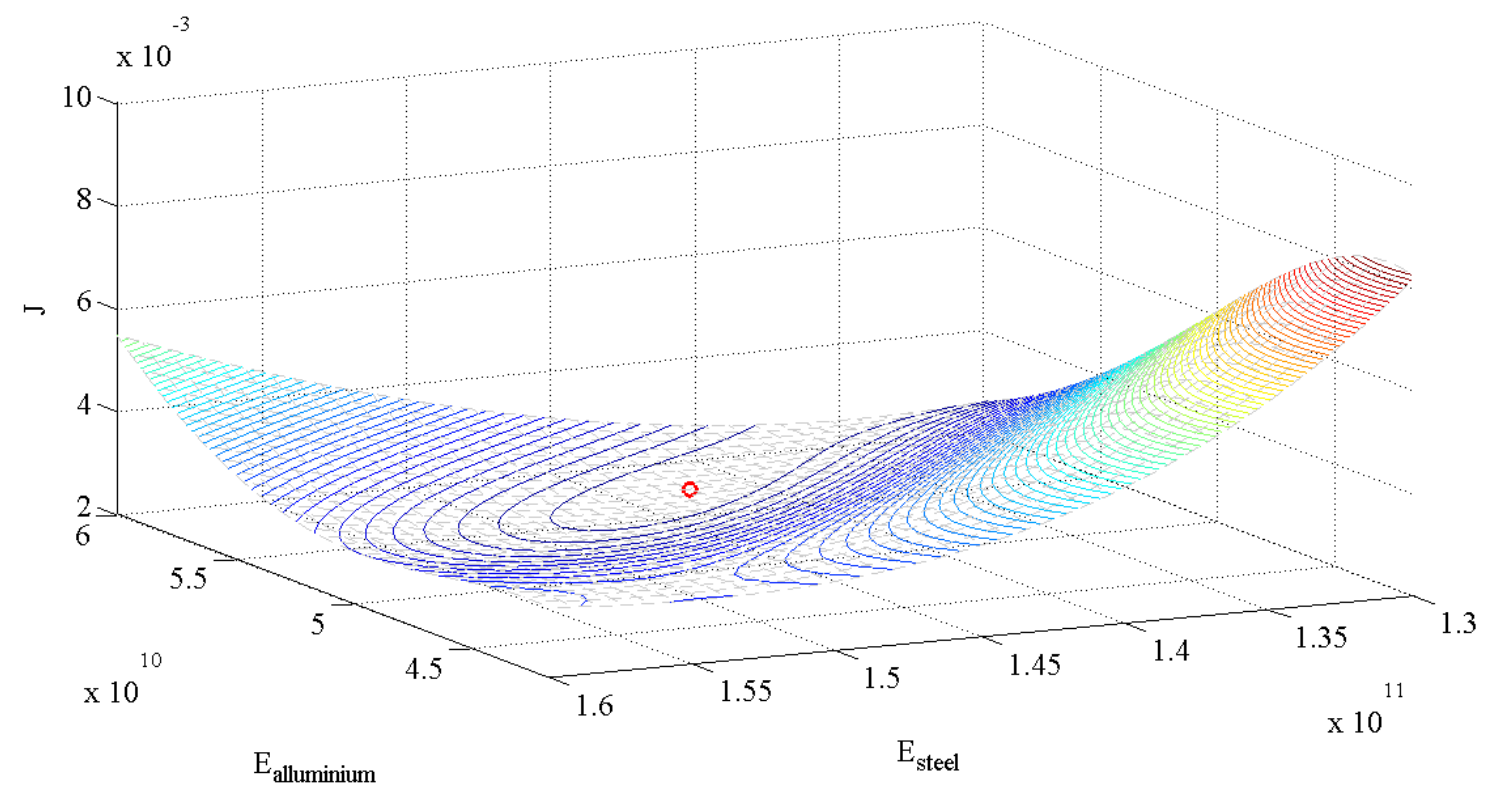

Figure $10 \mathrm{~J}$ function for the straight blade. Red circle indicates the optimum value. 


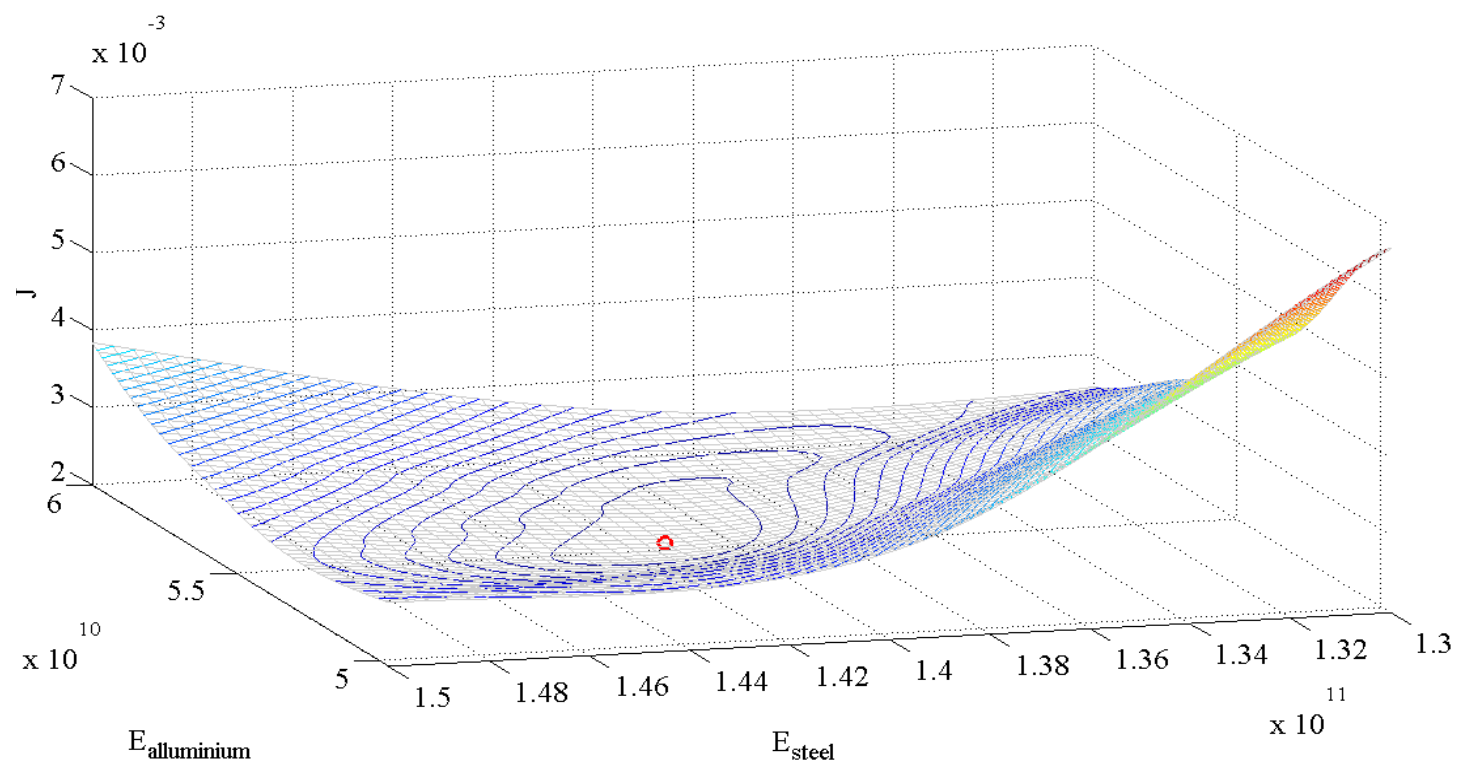

Figure 11. J function for the helical blade. Red circle indicates the optimum value.

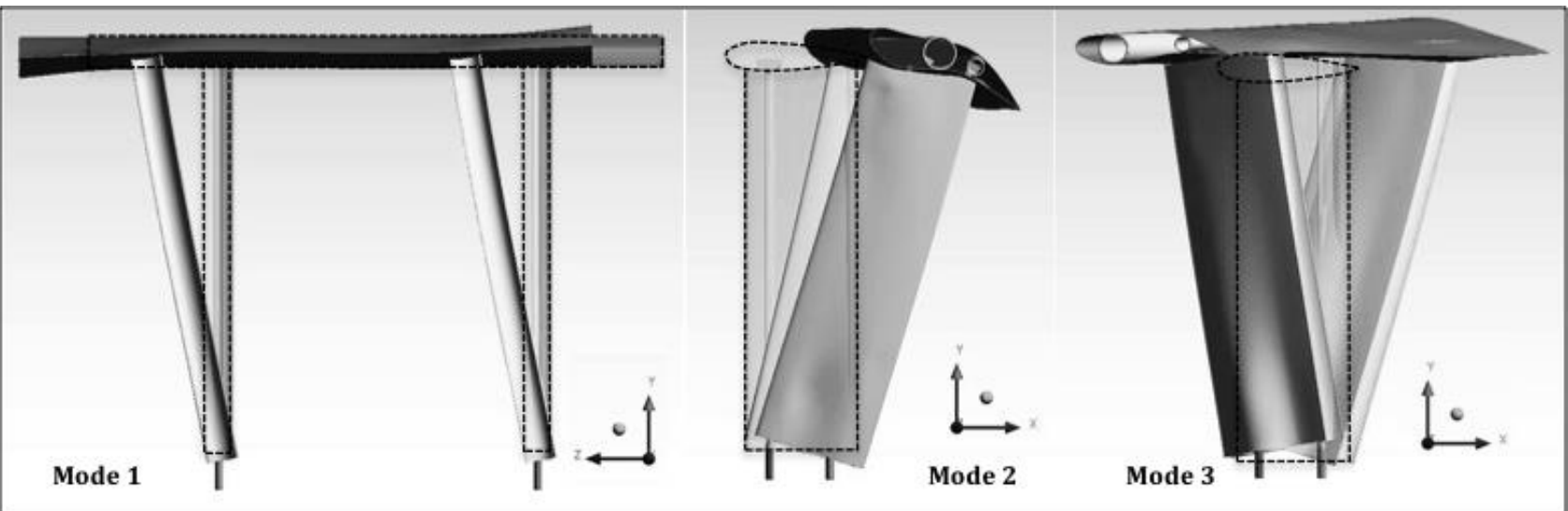

Figure 12. Numerical modal shapes - straight blade configuration.

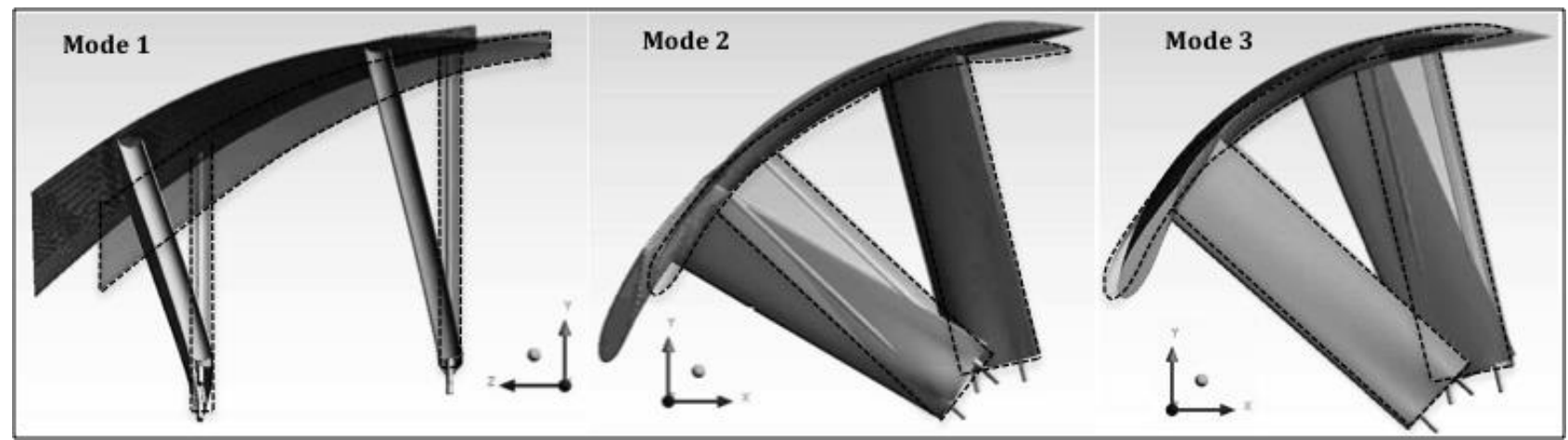

Figure 13. Numerical modal shapes - helical blade configuration.

\section{Static Structural behaviour and comparison}

The model updating, performed by choosing as parameters the Young's moduli of steel and aluminium components, allowed to adjust the material properties in the Finite Element models and 
to perform the static structural analyses for comparison between the two configurations analysed. The Von Mises equivalent stress distribution for the straight blade is shown in Figure 14. It is possible to point out that the main stresses arise at the connection between the steel barrels and the rotors and between the steel barrels and the aluminium cylindrical spars of the blade. More particularly the maximum stress is reached at the contact point between the front steel barrel and the front spar, as shown in Figure 14. As expected the main loads are related to inertia force due to rotation and that the weight of the blade influences the mechanical behaviour of the whole structure. The Von Mises equivalent stress distribution for the helical blade configuration is, instead, shown in Figure 15. It is possible to observe that, by considering for the helical blade the same rotational velocity as for the straight one, the maximum stress reduce from $\sigma_{\max }=114 \mathrm{MPa}$, obtained for the straight blade, to $\sigma_{\max }=36 \mathrm{MPa}$. Thus a reduction of weight from the straight blade to the helical one of about $75 \%$ leads to a maximum stress reduction of about $70 \%$. Moreover it is evidenced, for the helical configuration, very low stress in the bonding surfaces between the blade support and the blade itself.

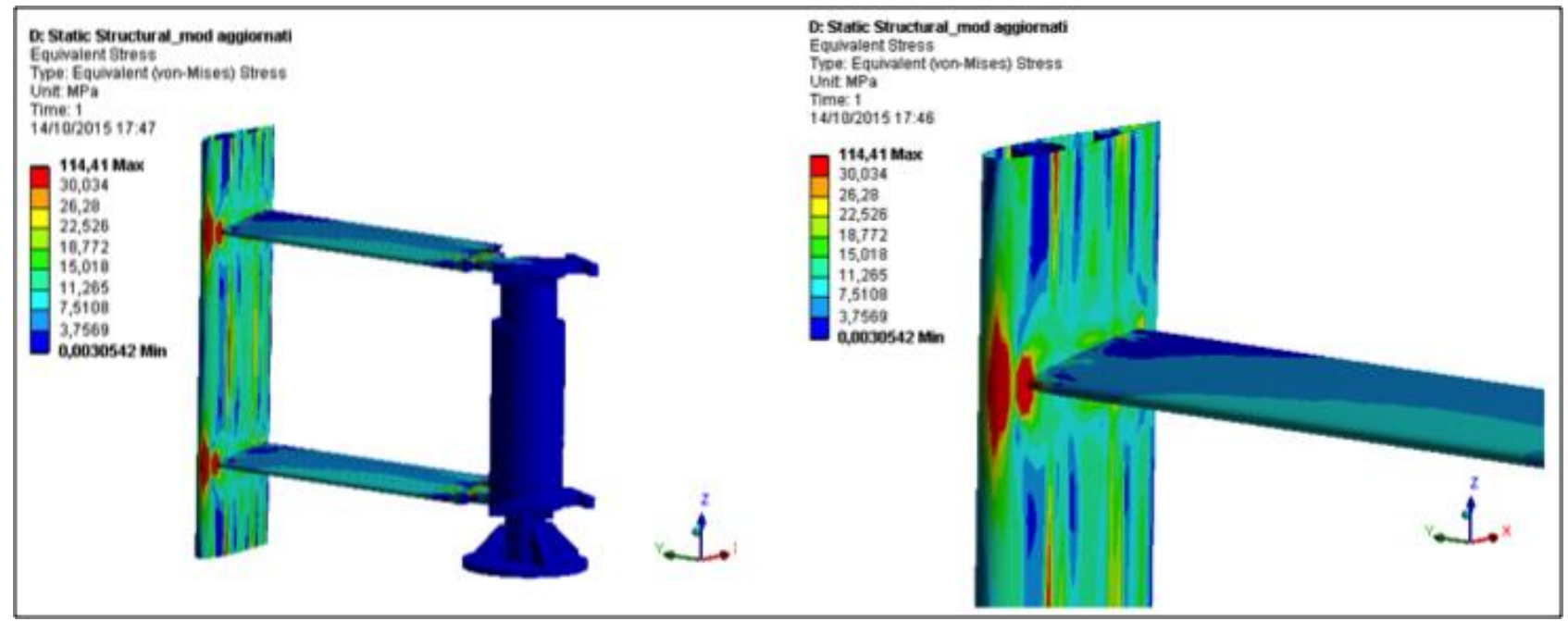

Figure 14. Von Mises equivalent stress distribution - Straigh Blade configuration.

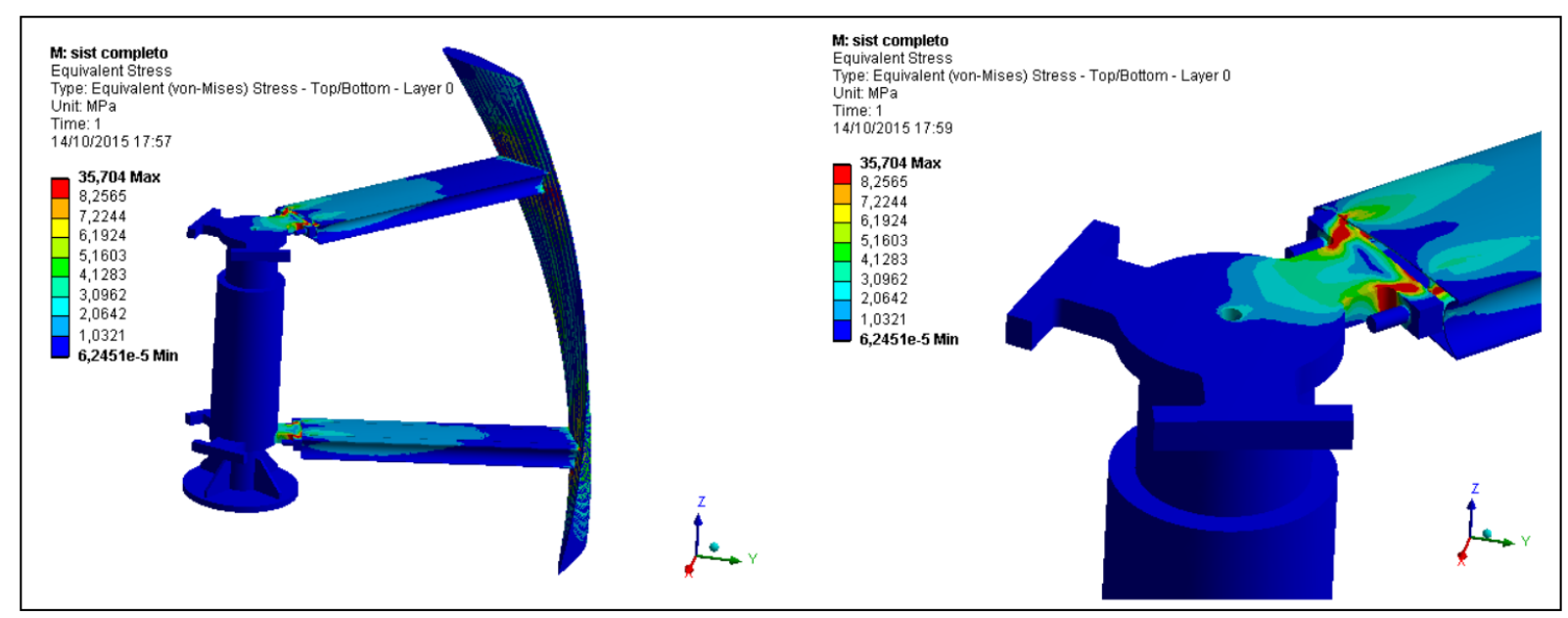


Figure 15. Von Mises equivalent stress distribution - Helical Blade configuration.

For the sake of completeness, the deformed shapes for both configurations are shown in Figure 16, plotted with a magnification factor equal to 150 . The maximum value obtained for the helical blade, although higher than the one obtained for the straight one, evidence a very stiff behaviour of the composite configuration used for the new turbine configuration that allowed to massively reduce the weight of the structure and stresses with an irrelevant increasing in the total deformation.

\section{Conclusions}

Numerical and experimental structural analyses of two different configurations of VAWTs have been proposed in this paper. The comparison has been performed between a straight blade metallic Darrieus generator and an helical blade composite Darrieus VAWT for both the dynamic and static structural behaviour. More particularly, firstly the modal characterization has been performed on the two turbine configurations both numerically, by means of the finite element code ANSYS ${ }^{\circledR}$ Mechanical $^{\mathrm{TM}}$, and experimentally.

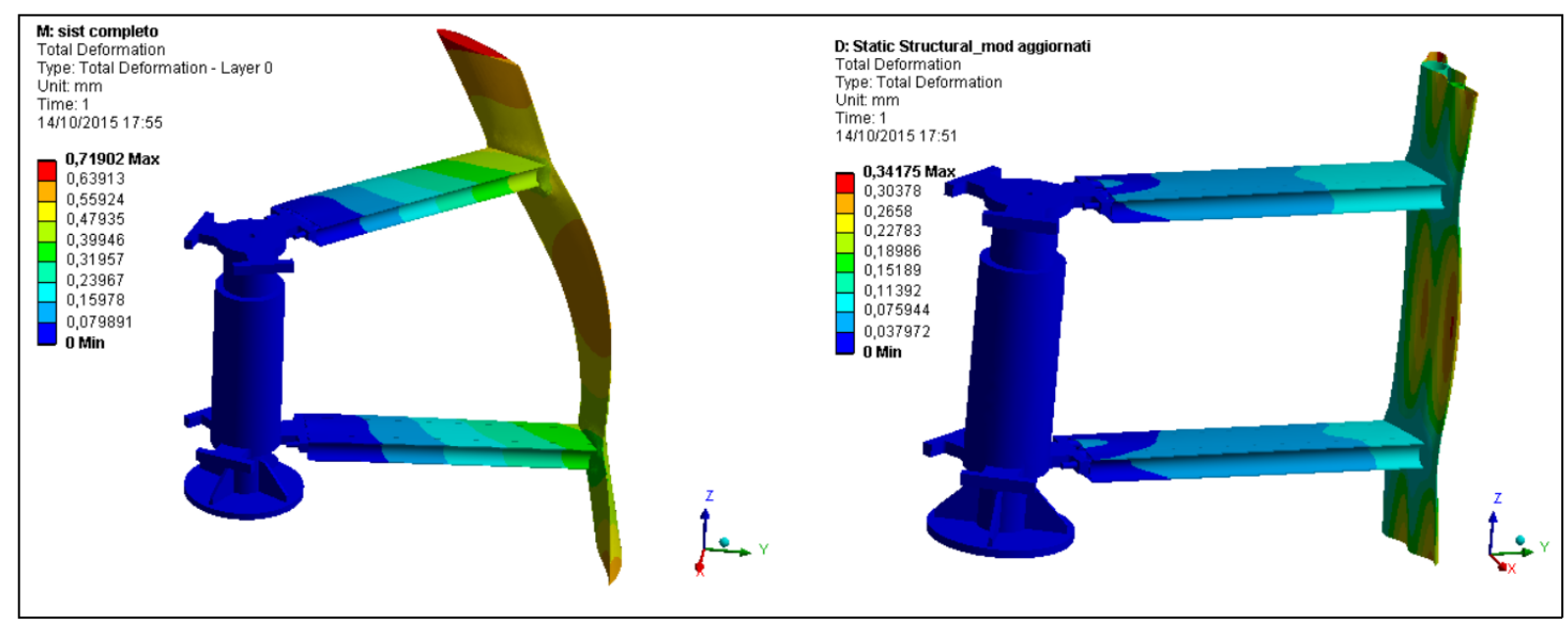

Figure 16. Deformed shape and total displacement distribution - helical blade (left), straight blade (right).

The results have been used for the Finite Element model updating. The updated Finite Element model has been thus used for the static analyses performed at a loading condition corresponding to the maximum angular velocity that the blade can experience. The structural analysis has pointed out that the Hybrid helical blade, designed and manufactured at the University of Enna "Kore", has allowed, if compared to the metallic straight blade, a weight reduction of about $75 \%$ and an huge reduction of the Von Mises stress acting on the structure, without affecting the overall stiffness of the assembled generator. 


\section{References}

[1] World energies Outlook Edition, International Energy Agency Pubblications, Paris France, 2014.

[2] H.J. Sutherland, D.E. Berg, T.D. Ashwill, A Retrospective of VAWT Technology, Sandia Report, SAND2012-0304; Sandia National Laboratories: Albuquerque, NM, USA, January 2012.

[3] C. Kaminsky, A. Fiulish, P. Kasprzak and W. Mokhtar, A CFD Study of a Wind turbine Aerodynamics, Proceedings of the 2012 ASEE .

[4] J. Castillo, Small-Scale Vertical Axis Wind turbine Design, Bachelor's Thesis, Tampere University of Applied Sciences, 2011.

[5] T. G. Carne, Donald W. Lobtiz, A. R. Nord A.Waston, Finite Element analysis and modal testing of a rotating wind turbine, Sandia Report 10/1982.

[6] M. O. L. Hansen - Aerodynamics of Wind Turbine second edition, Published by Taylor \& Francis, 2008.

[7] T. Burton, D. Sharpe, N. Jenkins, E. Bossanyi, Wind-Turbine Performance, In Wind Energy Handbook; John Wiley \& Sons Ltd.: Chichester, UK, 2002; pp. 173-207.

[8] A. Alaimo, A. Esposito, A. Milazzo, C. Orlando, F. Trentacosti, Slotted blades savonius wind turbine analysis by CFD, (2013) Energies, 6 (12), pp. 6335-6351.

[9] D.W. Lobitz and T.D. Ashwill, Aerolastic Effects in the Structural Dynamic Analysis of Vertical Axis Wind Turbines, Sandia Report SAND 85-0957, April 1986.

[10] D. Popelka, Aeroelastic Stability Analysis of a Darrieus Wind Turbine, Sandia Report SAND 82-0672, February 1982.

[11] A. F. Abdel, A. El-Sayed, Dynamics of vertical axis wind turbines (Darrieus Type), (1995) International Journal of Rotating Machinery, Volume 2, Issue 1, pp. 33-41.

[12] A. Bianchini, F. Cangioli, S. Papini, A. Rindi, E. Antonio Carnevale and L. Ferrari, Structural Analysis of a Small H-Darrieus Wind Turbine Using Beam Models: Development and Assessment, J. Turbomach 137(1), 011003 (Sep 04, 2014) (11 pages).

[13] A. Alaimo, A. Esposito, A. Messineo, C. Orlando, D. Tumino 3D CFD Analysis of a Vertical Axis Wind Turbine, (2015) Energies, 8 (4), pp. 3013-3033.

[14] Ansys Mechanical Theory and User's guide, (2013), ANSYS, Inc., Canonsburg.

[15] D. Foti, S. Ivorra Chorro, M. F. Sabbà, Dynamic Investigation of an Ancient Masonry Bell Tower with Operational Modal Analysis, The open Construcion and Building Technology journal, Vol. 6, pp. 384-391, 2012.

[16] C. De Valve, R. Pitchumani, Analysis of vibration damping in a rotating composite beam with embedded carbon nanotubes, Composite Structures, Vol. 110, pp. 289-296, 2014.

[17] M. Hajianmaleki, M. S. Qatu, Vibrations of straight and curved composite beams: A review, Composite Structures, Vol. 100, pp. 218-232, 2013.

[18] M. Şimşek, T. Kocatürk, Free and forced vibration of a functionally graded beam subjected to a concentrated moving harmonic load, Composite Structures , Vol. 90 (4), pp.465-473

[19] T. Marawla, Finite Element Model Updating Using Computational Intelligence Techniques, Application to structural Dynamics, Springer - Verlag London limited, 2010.

[20] G.P. Cimbellaro, S. Piantà, A. De Stefano - Output-Only modal identification of ancient L'Aquila city hall and civic tower, Journal of Structural Engineering, Vol. 138 (4), pp. 481 491, 2012.

[21] N.M.M. Maia, J.M. Montalvao Silva - Theoretical and experimental modal analysis - Jhon Wiley\&Sons Inc - 1997

[22] M.J. Friswell, J. E. Mottershead, Finite Element Model Updtating in Structural Dynamics, Kluwer Academic Publisher - 1994. 